\title{
ESENCIA Y MODALIDAD: HUSSERL Y KRIPKE *
}

\section{Claude Romano **}

\begin{abstract}
Resumen: En este trabajo se analizan las nociones de esencia en Husserl y Kripke marcando sus relaciones y diferencias. Husserl excluye una definición modal de la esencia, considerando que las necesidades incondicionadas tienen su fuente en las esencias y no recíprocamente. Por su parte, la concepción de Kripke obliga a repensar nociones supuestamente evidentes sostenidas por Husserl, como la equivalencia a priori/necesario, a posteriori/contingente, así como los lazos entre concebibilidad y posibilidad. Tomando distancia respecto de la posición de Husserl, se rechaza aquí la variación eidética como método único y se enfatiza finalmente el valor de la discusión razonada.
\end{abstract}

Palabras clave: esencia, modalidad, necesidad, verdad, método

Abstract: This paper analyzes Husserl's and Kripke's notions of essence in order to show relations and differences between them. Husserl excludes a modal definition of essence, considering that unconditional necessities have their origin in essences, but not reciprocally. Kripke's conception, on the other hand, obliges us to think again notions that were evident to Husserl, as the "a priori/necessary" and "a posteriori/contingent" equivalences, and also the links between conceivability and possibility. Finally, taking distance from Husserl's position and his eidetic variation, we emphazise reasoned discussion as the best method in this respect.

Key words: essence, modality, necessity, truth, method

* El origen de este texto, bajo el título "Essence et modalité: Husserl et Kripke", fue una conferencia dictada on-line en el Simposio con Especialistas, ciudad de Santa $\mathrm{Fe}$, el 11 de noviembre de 2010, anteprima de las VIII Jornadas Nacionales de Fenomenología y Hermenéutica, organizadas por el Círculo homónimo. La traducción ha sido realizada por la Licenciada María Cristina Greve.

** Maître de conférence Universidad de la Sorbonne, París IV. Entre sus libros cabe destacar: L'événement et le monde, Paris, PUF, 1998; L'événement et le temps, París, PUF, 1999; Il y a, París, PUF, 2003; Le chant de la vie, París, Éditions des Syrtes, 1999; Jérome Laurent et Claude Romano (éd), Le néant. Contribution à une bistoire du non-être dans la philosophie occidentale, París, PUF, "Épiméthée", 2006; Au coeur de la raison, la phénoménologie, París, Gallimard, 2010. 
La idea de confrontar a Kripke con Husserl sobre el problema de las relaciones entre esencia y modalidad parecerá sin duda a algunos extraña y hasta excéntrica. Por eso, permítaseme decir unas palabras acerca del marco más general en el que se inscribe este trabajo. Su tema constituye un momento en una voluminosa obra que aparecerá en Gallimard, y que se esfuerza por plantear a la fenomenología una pregunta análoga a la que Benedetto Croce le dirigiera a Hegel y a los hegelianos a principios del siglo pasado en su libro Ciò che è vivo e ciò che è morto della filosofia di Hegel, Bari, 1907. Mi trabajo comprende dos secciones principales, la primera confronta la fenomenología histórica con otras grandes corrientes de la filosofía del siglo $\mathrm{XX}$, desde el positivismo lógico hasta la filosofía gramatical wittgensteiniana y sus herederos analíticos. La segunda, más interna, sugiere algunos caminos que permitirían transformar la fenomenología desde dentro - no sin haber extraído previamente un cierto número de conclusiones positivas del rodeo por el diálogo con la filosofía analítica. Una parte importante de la primera sección gira alrededor de la cuestión de la esencia y su actualidad o inactualidad. Brevemente, defiendo allí una concepción de la esencia diferente a la de Husserl en dos puntos principales: primero, no se apoya en ninguna adhesión a un platonismo que vería en las esencias objetos o entidades de la naturaleza que se quiera; segundo, rechaza toda idea de una intuición eidética y considera que la actualización de las verdades de esencia no es mas que el primer paso y de ninguna manera la última palabra del trabajo fenomenológico.

Esta toma de distancia con respecto a Husserl se lleva a cabo no obstante sobre el fondo de un intento por reevaluar sus aportes más originales. Uno de esos aportes fundamentales me parece que reside justamente en la relación muy particular que establece entre esencia y modalidades.

Encontramos en Husserl dos clases de esencialismo: un esencialismo a propósito de individuos y un esencialismo a propósito de propiedades; en consecuencia, encontramos también dos tipos de esencias: esencias individuales y esencias generales. "El ser individual bajo todas sus formas, especifica él, es, con una palabra muy general, contingente (...) [Ahora bien] 
todo lo que es contingente implica precisamente la posesión de una esencia's. Por ejemplo, Sócrates posee una esencia individual que hace de él el individuo que es, diferente de otros individuos que comparten con él la propiedad común de ser hombres. Pero la propiedad de ser hombre posee también una esencia que hace de esta propiedad la propiedad que ella es, por contraste con otras propiedades ${ }^{2}$.

¿Cómo caracterizar más precisamente la esencia como tal? Para un objeto individual, consiste, escribe Husserl, en "su fondo (seinen Bestand) permanente de predicados esenciales que le sobrevienen necesariamente (en tanto "que es tal como en sí mismo es')"3.

A primera vista, esta caracterización de la esencia -sin duda la más precisa que se encuentra en todo el corpus husserliano- es circular. Definir la esencia por un fondo de predicados esenciales, es definir la esencia por la esencia. No obstante, detenerse en esta circularidad aparente sería querer ignorar lo que genera todo el interés en esta definición, a saber, la precisión contenida en el paréntesis: la esencia es la serie de predicados esenciales a una cosa (o a una propiedad), es decir, la serie de los predicados necesarios para que la cosa misma sea "tal como en ella misma es (als 'Seiendem, wie er in sich selbst ist)". Esta precisión es decisiva. En efecto, basta reemplazar "predicados esenciales" por "predicados necesarios para que una cosa sea lo que ella es" o por "predicados necesarios para la identidad de esa cosa" para que la apariencia de circularidad de la definición en su forma abreviada desaparezca. Hablar aquí de lo que es una cosa, de su ti esti, o incluso de lo que es ser esa cosa, es decir, de su identidad, no equivale a hablar de la identidad en el sentido lógico-formal de la relación de identidad que esa cosa mantiene consigo misma o con otra cosa. La esencia en términos aristotélicos es lo

${ }^{1}$ Edmund Husserl, Husserliana (se abreviará de aquí en más “Hua"), III, 1, 2 , p. 12 ; trad. francesa Paul Ricoeur, Idées directrices pour une phénoménologie, Paris, Gallimard, coll. Bibliothèque de Philosophie, 1950, pp. 16-17.

2 En el léxico platonizante de Husserl, quien concibe las propiedades como entidades generales, es decir, como ideas, esta afirmación equivale a la de Jean Hering, Bemerkungen über das Wesen, die Wesenbeit und die Idee, Jabrbuch für Pbilosophie und Pbänomenologische Forscbung, Vierter Band, 1921, p. 497: "No se ve por qué sólo los objetos individuales deberían tener su esencia. En efecto, no solamente cada objeto particular, sino también cada 'idea' tiene su esencia".

${ }^{3}$ Hua, III, 1, pp. 12-13; trad. citada (modificada), pp. 17-18. 
que responde a la pregunta $¿ t i$ esti? a saber, el conjunto de predicados que delimitan el to ti ên einai, el "lo que es" la cosa, o mejor, el "lo que es ser [esa cosa]" o aún más, el "lo que es [para esa cosa] ser la cosa que ella es [que ella era ${ }^{4}$ " -lo que el latín expresará como quidditas. La identidad de la que aquí se trata es, por consiguiente, aquella que comparece en una definición (borismos) $)^{5}$. En consecuencia, una propiedad es esencial si es necesaria para que la cosa sea lo que ella es, y, en el caso contrario, es accidental. Puesto que los objetos individuales pueden ser los depositarios de una esencia tanto como las propiedades generales, se distinguirá la esencia individual, es decir, el conjunto de los predicados necesarios para que un individuo sea el individuo que es, distinto de cualquier otro individuo que pertenece al mismo género, y la esencia genérica, el conjunto de los predicados necesarios para que un individuo sea el género de individuo que es, o para que una propiedad sea el género de propiedad que es.

Pero, ¿qué significa aquí esta cláusula: “necesario para que $x$ sea lo que es"? Husserl aporta sobre este punto una precisión importante: la esencia se define en términos de necesidad, pero la necesidad no basta para definir la esencia. "Ahora bien, tiene importancia, escribe, respetar las distinciones de sentido y ante todo no designar a la generalidad de esencia (Wesensallgemeinheit) misma como necesidad (Notwendigkeit) (como se acostumbra a hacer)" 6 . Este inciso es decisivo en la medida en que establece una demarcación rigurosa entre la necesidad de esencia y la necesidad a secas. Husserl excluye una definición estrictamente modal de la esencia. Decir que un predicado es esencial, en efecto, es decir que es necesario, pero la conversa no es verdadera: no basta que un predicado sea necesario para que sea esencial. O bien, para decirlo de otro modo, una proposición de esencia es una proposición verdadera en todos los mundos posibles, por tanto, necesaria; pero toda proposición necesaria, es decir, verdadera en todos los mundos posibles, no es sin embargo una proposición de esencia.

${ }^{4}$ Como se sabe, la extraña fórmula de Aristóteles, to ti ên einai, se caracteriza por el doble empleo de eînai, cuyo primer caso está en imperfecto.

${ }^{5}$ Aristóteles, Metafísica, Z, 5, 1031 a12: esti tou horismos bo tô̂ ti ên einai logos. "la definición es la expresión de lo que es ser una cosa [de la esencia]".

${ }^{6} \mathrm{Hua}, \mathrm{III}, 1, \mathbb{\int} 6$, p. 19; trad. citada (modificada), p. 29. 
¿Por qué razón? Husserl no responde expresamente a esta pregunta en el $\ 6$ de Ideen... I, pero uno de sus discípulos, Jean Hering, se esfuerza por hacerlo en un texto de 1921 que constituye un largo comentario al capítulo primero de Ideen... I. Hay propiedades, señala, que resultan necesariamente de la esencia aún no perteneciendo a su contenido: "De la esencia de una esfera de un metro de diámetro, se infiere absoluta y necesariamente que ella es más pequeña que un cubo cuya arista mide un metro; ahora bien, esto no pertenece a su esencia; pues su esencia es lo que ella es, existan o no otros sólidos"7. Así, la pareja necesario/contingente no coincide con la pareja esencial/accidental, porque la mención de la esencia hace intervenir un elemento extra-lógico, un elemento de pertinencia de la propiedad considerada, el cual es contenido justamente en la cláusula "para que la cosa sea lo que ella es" -no teniendo este elemento ningún equivalente desde el punto de vista de la lógica modal. La verdad de la proposición que atribuye una propiedad esencial (o que atribuye esencialmente una propiedad) no es necesaria simpliciter, ella es necesaria en virtud de la identidad del objeto. En rigor, uno se podría poner de acuerdo perfectamente sobre todas las propiedades necesarias sin ponerse de acuerdo sobre las que son esenciales. Para tomar otro ejemplo, es una verdad de la teoría de conjuntos que, necesariamente, todo elemento pertenece al menos a un conjunto. Entonces es necesario que tal gato (Félix) pertenezca a un conjunto (por ejemplo, al singleton que contiene a Félix como su único elemento). Pero no es sin embargo esencial a Félix, ni a los gatos en general, pertenecer a conjuntos cualesquiera que sean. Es esencial al singleton que contiene a Félix como su único elemento que contenga a Félix como su único elemento, como no es de ninguna manera esencial a Félix que pertenezca a ese singleton. Tenemos aquí una asimetría que es propia de las afirmaciones de esencia. En la lógica modal nada corresponde a esta asimetría, ya que la proposición según la cual "es necesario que el singleton 'Félix' contenga a Félix" es indiferente al hecho de que uno u otro -el gato o el conjunto- ocupe la función de sujeto lógico de la proposición.

Se desprende de estas consideraciones que Husserl rechazaría una caracterización modal de la esencia como la que privilegian numerosos autores contemporáneos, según la cual una propiedad de un objeto podría

7 Jean Hering, "Bemerkungen über das Wesen, die Wesenheit und die Idee", Jabrbuch für Pbilosopbie und Phänomenologische Forschung, Vierter Band, 1921, p. 500. 
ser llamada esencial si y solamente si es necesario (es decir verdadero en todos los mundos posibles) que este objeto posea esta propiedad ${ }^{8}$. Husserl aceptaría decir que, si una propiedad es esencial a un objeto, es necesario que este objeto posea esta propiedad (o que posea esta propiedad si él existe), pero rechazaría la conversa. Asistimos así a una verdadera inversión de perspectiva con respecto a cualquier caracterización modal de la esencia, ya que es conveniente decir en lo sucesivo que las necesidades incondicionadas tienen su fuente en las esencias, y no recíprocamente. En el vocabulario de Husserl, las necesidades materiales se enraízan en las "esencias materiales" y las necesidades formales en las "esencias formales", constituyendo cada una de estas dos clases de esencia el objeto propio, respectivamente, de las ontologías materiales y formales. Recordemos que por "ontología" Husserl entiende una doctrina a priori del objeto" (donde “objeto" debe entenderse en el sentido más formal de "sujeto de juicios predicativos verdaderos"10). En la medida en que las esencias formales (obtenidas por sustitución de variables de todos los términos materiales, o aun por "formalización") no se aplican más que a la forma pura del algo en general, la ontología formal -como la lógica formal11 - es regida por necesidades analíticas. Las ontologías materiales, en cambio, hacen intervenir consideraciones sobre la "naturaleza" de sus objetos, tienen en cuenta la dependencia de estos objetos respecto de las propiedades generales que delimitan las diferentes regiones de la realidad (cosa material, vivencia, conciencia, sonido, color,

8 Por ejemplo, Alvin Plantinga, en una obra que contribuyó a una cierta reevaluación del esencialismo, The Nature of Necessity, Oxford, Clarendon Press, 1974, propone una definición modal de ese género: "What is it [...] to say that a certain object has a property essentially or necessarily ? That, presumably, the object in question could not conceivably have lacked the property in question; that under no possible circumstances could that object have failed to possess that property" (p. 11). Cfr. también Penelope Mackie, How Things Might have been: Individuals, Kinds, and essential properties, Oxford University Press, 2006, p. 2.

9 Hua, XVII, p. 82; trad. francesa Suzanne Bachelard, Logique formelle et logique trascendentale. Essai d'une critique de la raison logique, Paris, PUF, 1957, p. 108.

${ }^{10}$ Hua, III, 1, p. 15; trad. citada, p. 22. Cf. también Hua, XVII, p. 77; trad. citada, pp. 101-102.

11 La lógica formal trata sobre los conceptos, las proposiciones, las inferencias tomadas como puras significaciones; la ontología formal trata sobre los objetos formales que corresponden a esas significaciones. 
etc.); por consiguiente, estas ontologías son regidas por legalidades sintéticas a priori.

La inversión de perspectiva, en virtud de la cual la esencia no es definida en términos de modalidad sino que las modalidades encuentran su fundamento en la esencia, constituye toda la originalidad de la concepción husserliana. Esto es enunciado en el $\ 6$ de Ideen... I. Encontramos en ese pasaje las dos afirmaciones siguientes. a) Aunque la generalidad eidética y la necesidad eidética sean correlatos rigurosos, ya que la generalidad eidética es una generalidad ilimitada (valiendo para todos los mundos posibles) y que la necesidad de una proposición de esencia significa su verdad en todos los mundos posibles, no se puede identificar la generalidad eidética con la necesidad en general. b) Esta especie particular de necesidad que es la necesidad de esencia (Wesensnotwendigkeit) es una "particularización" (Besonderung) "de un estado de cosas dotado de generalidad eidética"12, es decir de "leyes de esencia (Wesensgesetzen)"13. La esencia está pues en el fundamento de toda necesidad en el sentido fuerte del término, de toda necesidad incondicionada. Así, por ejemplo, la proposición necesaria según la cual "todo cenicero es un cuerpo material", e incluso aquella según la cual "todo cenicero posee una extensión espacial", obtienen su necesidad de los "axiomas regionales" que rigen la esencia genérica más elevada del dominio material correspondiente, a saber, la esencia cosa material. Puesto que deriva de la esencia de la cosa material en general que toda cosa material posea una extensión espacial ${ }^{14}$, y puesto que todo cenicero es una cosa material, se infiere que todo cenicero es también un objeto espacialmente extenso, de modo que la necesidad de esta última proposición se deriva de la de los "axiomas regionales", es decir, de las verdades de esencia más universales de la región considerada. Lo mismo sucede con las necesidades de esencia formales (analíticas) que tienen su fuente en las esencias formales: " $2+2=4$ ", "no hay todo sin parte", etc. En suma, como lo observa Mohanty, la singularidad de la posición de Husserl no es solamente el afirmar que las necesidades de esencia son irreductibles a las modalidades lógicas, sino agregar que las modalidades lógicas son un caso de necesidad de esencia: "Para Husserl, la posibilidad de esencia es el concepto clave, la 'posibilidad lógica' está subordinada a ésta; la

12 Hua, III, 1, p. 19; trad. citada, p. 29.

13 Hua, III, 1, p. 20; trad. citada (modificada), p. 31.

${ }^{14}$ Hua, III, 1, p. 24; trad. citada, p. 37. 
idea de una 'posibilidad esencial' que sea irreductible a la posibilidad lógica es su contribución original"15.

Una vez visto este primer punto, queda por examinar un segundo punto, no menos crucial, que es el siguiente: a los ojos de Husserl, como para la mayoría de sus herederos, no hay ninguna duda de que las descripciones de esencia en general y las descripciones de esencia de los fenómenos en particular son a priori. ¿Pero esta tesis del carácter a priori de las descripciones de esencia es sostenible? La pregunta parece con mayor razón justificada por cuanto la filosofía analítica contemporánea ha visto el desarrollo de un nuevo esencialismo que se resume en la afirmación de Kripke según la cual "se puede muy bien descubrir la esencia empíricamente"16. Según Kripke, una afirmación tal como "el agua es $\mathrm{H}_{2} \mathrm{O}$ " es seguramente un descubrimiento empírico; lo que no le impide ser necesario en el sentido más fuerte de la palabra. Ella vale para todos los mundos posibles donde el agua exista. Y como la esencia es determinada por Kripke en términos modales, esta proposición necesaria relativa a la constitución molecular del agua es también, por lo mismo, una proposición de esencia.

¿Es posible sostener todavía, después de Kripke, una doctrina que postule esencias a priori? ¿El esencialismo de Husserl, con las particularidades que he mencionado, sucumbe a una crítica proveniente del esencialismo modal de Kripke?

En el pasaje donde intentaba explicar por qué la necesidad de la esencia es irreductible a la necesidad a secas, Jean Hering proporcionaba no uno sino dos ejemplos de necesidad que derivan de la esencia sin ser sin embargo necesidades de esencia. Ya hemos examinamos el primero de esos ejemplos: "De la esencia de una esfera de un metro de diámetro, se infiere absoluta y necesariamente que ella es más pequeña que un cubo cuya arista mide un metro; ahora bien, esto no pertenece a su esencia; porque su esencia es lo que ella es, existan o no otros sólidos". El texto prosigue así:

15 J. N. Mohanty, "Phenomenology and the modalities", in Logic, Truth, and the modalities, Dordrecht-Boston-London, Kluwer Academic Publishers, 1999, p. 178.

16 Saul A. Kripke, Naming and Necessity, trad. francesa Pierre Jacob et François Recanati, La logique des noms propres, Paris, Éditions de Minuit, 1982, p. 99. 
Necesario a la esencia en relación con ciertas circunstancias es, por ejemplo, la caída de una piedra (aquella se revela necesaria a la esencia en cuanto se cumplen ciertas condiciones). También, fundada en la esencia, pero no produciéndose necesariamente, es por ejemplo la caída de una piedra pura y simplemente, abstracción hecha de toda condición determinada. Es visible que este acontecimiento puede producirse sobre el fundamento de la esencia de la piedra. Seguramente, la esencia prefigura qué destino su portador puede sufrir, en qué relaciones puede encontrarse ${ }^{17}$.

La necesidad de la que se trata en el primer ejemplo es una necesidad pura, es decir, una necesidad a priori. En el segundo ejemplo, al contrario, tenemos un caso de necesidad empírica. Ni la una ni la otra, nos dice Hering, dependen del contenido de la esencia propiamente dicho, aunque tengan -de manera diferente- su fuente en ella. No obstante, Hering no especifica mejor cómo necesidades empíricas pueden tener su fundamento en necesidades de esencia.

Para examinar este problema, hay que volver a los lazos originales que Husserl percibe entre esencia y modalidad. Como se dijo, toda necesidad en sentido fuerte, es decir toda necesidad incondicional (es necesario, en ese sentido, lo que es verdadero en todos los mundos posibles) deriva de la esencia: una proposición es necesaria porque es esencial y no inversamente. Así, una verdad material necesaria tal como "toda estatua es extensa" es una verdad necesaria porque deriva de ese axioma material de la región cosa material en general. Esa proposición es verdadera en todos los mundos posibles y su negación es un contrasentido material ya que el estado de cosas que ella expresa, el de una estatua desprovista de extensión espacial, es inconcebible.

Las necesidades incondicionadas derivan de esencias puras y las esencias puras (que es conveniente distinguir de simples generalidades eidéticas), son todas a priori, sean ellas formales o materiales ${ }^{18}$. Por consiguiente, las necesidades de esencia son ellas mismas a priori: "Una

${ }^{17}$ Jean Hering, Bemerkungen über das Wesen, $₫ 3$ (2), p. 500 .

${ }^{18}$ Hua, Bd. XVII, p. 255, nota 1; trad. citada, p. 332, nota (a). 
necesidad a priori [es] una necesidad que se funda en las esencias puras"19. ¿Por qué razón? La respuesta es que no es ni siquiera posible concebir un estado de cosas opuesto al estado de cosas necesario según el cual toda cosa material es extensa espacialmente. El conocimiento de este estado de cosas no descansa sobre ninguna generalización empírica, sobre ninguna hipótesis que pudiera ser invalidada por una nueva experiencia; una contraexperiencia (un contra-ejemplo), en efecto, no es ni siquiera pensable aquí.

Esta observación nos aclara, por lo mismo, el sentido particular del "a prior" en los escritos de Husserl y sus herederos. Esta "expresión de significación múltiple"20, como la llama Husserl, debe entenderse de la siguiente manera: una verdad es a priori y, por lo tanto, incondicionalmente necesaria (verdadera en todos los mundos posibles) si, y solamente si, ella no puede ser invalidada por ninguna experiencia concebible (por consiguiente, si no descansa sobre ninguna generalización empírica). No sería una objeción, por ejemplo, hacer notar en contra de lo que dice Husserl, que, para conocer una verdad formal-analítica del tipo: " $A \& B$ es verdadero si $A$ es verdadero y $B$ es verdadero, y falso en los tres otros casos", puedo remitirme a un manual de lógica, o incluso a un rumor y a la opinión pública, y consecuentemente, conocer esta verdad a posteriori. "A priorn", tal como esta expresión es empleada por Husserl, no caracteriza la manera con la que llego de becho a adquirir un conocimiento, sino la manera con la que puedo por derecho adquirirlo. Una verdad (un conocimiento) es a priori si puedo adquirirlo sin apelar a una generalización inductiva, es decir si no es necesario recurrir a la experiencia para adquirirla. Lo que no implica en ningún caso que yo no pueda también recurrir a la experiencia (en ese caso, hojear un manual de lógica) para aprender esta verdad. $Y$ esto vale, naturalmente, tanto para verdades analítico-formales como para verdades materiales.

$\mathrm{Si}$ las leyes de esencia son leyes necesarias a priori, las leyes de la naturaleza que son de la incumbencia de las ciencias empíricas no son leyes necesarias en el mismo sentido. Son simples regularidades contingentes. "Las leyes de la naturaleza, escribe Husserl, expresan sólo una regulación de

${ }^{19}$ LU III, $\$ 4$; Hua, Bd. XIX/2, p. 237; trad. fr. Hubert Élie, Arion Lothar Kelkel y René Schérer, Recherches logiques, Paris, PUF, 1972, II, 2, p. 15.

${ }^{20}$ Hua, Bd. XVII, p. 255, nota 1; trad. citada, p. 332. 
hecho (faktische Regelungen)"21. Y, por lo tanto, "las 'leyes de la naturaleza', leyes en el sentido de las ciencias empíricas, no son leyes de esencia (leyes ideales, leyes a prion), una necesidad empírica no es una necesidad de esencia"22. O aún más, ya que la necesidad se puede formular en términos de generalidad (es necesario lo que es verdadero en todos los mundos posibles, es contingente lo que es verdad por lo menos en un mundo posible), "no hay que confundir la generalidad ilimitada de las leyes de la naturaleza con la generalidad de esencia" 23 . Las regularidades contingentes de las leyes de la naturaleza valen en este mundo, pero otros mundos gobernados por diferentes leyes son pensables. Por ejemplo, es perfectamente pensable que la constitución molecular del agua tal como ella nos es revelada de manera empírica sea $\mathrm{H} 3 \mathrm{O}$. $\mathrm{O}$ aún mas, no es un absurdo intrínseco imaginar una situación experimental en la que el agua no disolviera el cloruro de sodio, un mundo donde las físicas constantes tuvieran valores ligeramente diferentes de sus valores efectivos y donde las moléculas de agua no fueran susceptibles de vencer las fuerzas electrostáticas que aseguran la cohesión de los cristales de sal. Las regularidades de la naturaleza son "necesarias", si uno quiere, pero en un sentido diferente: bajo la condición de que el mundo sea lo que él es. Su necesidad es entonces condicional.

Esta necesidad condicional, esta necesidad de becho, se enraíza sin embargo a su vez en verdades de esencia. En efecto, para que regularidades de hecho sean regularidades reales de este mundo, hace falta que ellas sean, en él, regularidades posibles. Para que una verdad empírica tal como "la composición molecular del agua es $\mathrm{H}_{2} \mathrm{O}$ " describa un estado de cosas real, hace falta primero que describa un estado de cosas posible. Para ser posibles, estos hechos y estas regularidades no deben ser ni contradicciones formales (analíticas), ni contrasentidos materiales. Dicho de otro modo, en virtud del axioma según el cual "el conocimiento de las 'posibilidades' debe preceder al conocimiento de las realidades (der Wirklicbkeiten)"24, hay que sostener que las verdades empíricas y las necesidades empíricas dependen de las verdades puras y de las necesidades puras, es decir, de verdades de esencia y de necesidades de esencia. Como lo subraya Husserl en el pasaje principal de su

${ }^{21}$ Hua, Bd. III, 1 , p. 12 ; trad. citada, p. 17.

${ }^{22}$ LU III, $₫ 7$; Hua, Bd. XIX/2, p. 243; trad. citada, II, 2, p. 22.

${ }^{23}$ Hua, Bd. III, 1, p. 20; trad. citada (modificada), $\$$ 6, p. 30.

${ }^{24}$ Hua, Bd. III, 1, p. 178; trad. citada (modificada), p. 269. 
caracterización de la esencia que ya comentamos largamente, un objeto individual, un esto (ein Dies da) contingente, "del hecho de que tiene 'en simismo' tal o cual constitución, (...) tiene su especificidad (Eigenart), su fondo permanente de predicados esenciales que le sobrevienen necesariamente (en tanto 'que es tal como en sí mismo es'), de tal modo que otras determinaciones, secundarias y relativas, puedan advenirle" 25 . Es sobre este punto que también insistía Hering. Todo hecho contingente y toda regularidad contingente no pueden ser tales más que si satisfacen primero a verdades de esencia: "Todo lo que es contingente implica precisamente la posesión de una esencia"26.

El conocimiento de las esencias precede y funda todo conocimiento empírico. Como lo explica Husserl, "si toda ciencia eidética es por principio independiente de toda ciencia de hecho, sucede lo contrario, en cambio, respecto de lo que es verdadero para las ciencias de hecho. No hay ninguna que, habiendo alcanzado su pleno desarrollo de ciencia, pueda quedar pura de todo conocimiento eidético y, por tanto, independiente de las ciencias eidéticas, sean éstas formales o materiales" 27 . Así, todo hecho debe conformarse a los requisitos de la ontología formal, desde luego, pero también a los requisitos de las ontologías materiales. "Todo hecho incluye un fondo esencial (Wesensbestand) de orden material, y toda verdad eidética perteneciente a las esencias puras contenidas en él debe engendrar una ley que rija los casos empíricos dados, así como todo caso posible en general" 28 .

Podemos entonces presentar de manera sinóptica la doctrina de Husserl a través de las tesis siguientes:

1) Las necesidades puras, las posibilidades e imposibilidades puras derivan de la esencia y de leyes de esencia.

2) Las esencias puras (formales y materiales) son a priori.

3) Las necesidades de esencia, posibilidades e imposibilidades de esencia son a priori.

4) Ellas se subdividen en formales (analíticas) y materiales (sintéticas $a$

25 Hua, Bd. III, 1, pp. 12-13; trad. citada, p. 17-18 (subrayamos).

${ }^{26}$ Hua, Bd. III, 1, p. 12; trad. citada, p. 17.

${ }^{27}$ Hua, Bd. III, 1, p. 22; trad. citada (modificada), p. 34.

${ }^{28}$ Hua, Bd. III, 1, p. 23; trad. citada (modificada), pp. 34-35. 
prior): las imposibilidades formales son las contradicciones; las imposibilidades materiales, los "contrasentidos materiales".

5) Las esencias delimitan los dominios de lo posible y de lo imposible.

6) Los hechos empíricos y las legalidades empíricas son contingentes.

7) Las necesidades empíricas no son leyes de esencia; son necesidades condicionales (hipotéticas) y no necesidades incondicionadas.

8) La realidad o la efectividad de un hecho o de una ley contingente presupone su posibilidad.

9) El conocimiento de las posibilidades precede el conocimiento de las realidades.

10) Todo lo que es contingente implica la posesión de una esencia.

11) El conocimiento de posibilidades e imposibilidades de esencia debe preceder al conocimiento de posibilidades e imposibilidades de hecho (empíricas). Las necesidades empíricas tienen su fundamento en necesidades puras.

12) Las verdades empíricas de ciencias empíricas encuentran su fundamento en verdades de esencia.

La cuestión que se plantea es la de saber si este conjunto de tesis es coherente y si algunas objeciones no le serían fatales. Todo este edificio se apoya, en efecto, sobre la idea de que las leyes de la naturaleza son leyes contingentes, es decir, leyes tales que sería concebible que no pudieran aplicarse en algunos mundos posibles. O, más profundamente, todo este edificio se apoya sobre la equivalencia entre a priori y necesario (absolutamente hablando) y a posteriori y contingente (necesario solamente hasta tanto lo que suceda no sea invalidado por una nueva experiencia). Para Husserl, lo que es epistémicamente contingente (a posterior), es decir, lo que es tal que se lo habría podido descubrir diferente a lo que es, es también ontológicamente contingente. Asimismo, lo que es epistémicamente necesario (a prior), es decir, lo que es tal que es inconcebible que fuese diferente, es también y por eso mismo, ontológicamente necesario. Según su fórmula, el "no-poder-representarse-de otro modo" significa la necesidad 
objetiva de un "no-poder-ser-de otro modo"29. ¿Pero esta doble equivalencia del a priori y de lo necesario, del a posteriori y de lo contingente es sostenible? ¿Por ser de origen empírico, las verdades empíricas de las ciencias de la naturaleza son verdades tales que sería concebible que no fueran el caso? $¿$ No son ellas por el contrario verdades necesarias en el sentido fuerte, "metafísico", del término, como lo anticipa Kripke?

Esta cuestión es difícil pues, como lo vamos a ver, la conceptualidad de Kripke está tan alejada de la de Husserl que es bastante delicado confrontar sus posiciones. Nos contentaremos en lo que sigue con observaciones que no pretenden ser ni exhaustivas ni sistemáticas.

El punto nodal de la demostración de Kripke consiste en disociar lo a priori y lo a posteriori, por una parte, y lo necesario y lo contingente, por la otra, haciendo valer que las primeras nociones son epistémicas, mientras que las segundas son modales. Su argumentación consiste entonces en atacar la doble equivalencia que hemos observado en Husserl. En efecto, Kripke sostendrá por una parte que la verdad de una proposición de identidad tal como "agua $=\mathrm{H} 2 \mathrm{O}$ " es a posteriori, por tanto, epistemológicamente contingente: otro descubrimiento empírico a propósito de la constitución molecular del líquido que fluye en nuestros ríos es concebible. Con esto, Kripke no quiere decir que la constitución molecular del agua habría podido ser diferente, sino que el líquido que fluye por nuestros ríos habría podido revelarse como diferente al agua. Por otra parte, afirma que el carácter a posteriori de la verdad "agua $=\mathrm{H}_{2} \mathrm{O}$ " no entraña su carácter metafísicamemente contingente: es un carácter de la esencia del agua que ella tenga como composición química $\mathrm{H} 2 \mathrm{O}$, porque la identidad "agua $=\mathrm{H}_{2} \mathrm{O}$ " es verdadera en todos los mundos posibles. El hecho de que habríamos podido hacer otro descubrimiento concerniente a la constitución molecular del líquido que fluye por nuestros ríos no entraña, una vez establecido que el agua es $\mathrm{H} 2 \mathrm{O}$, que esta proposición de identidad sea contingente, es decir, que sea concebible que el agua tenga en otros mundos posibles $-O$, según la interpretación minimalista de "mundo posible" que adelanta Kripke, en otras situaciones contrafácticasuna constitución molecular diferente; porque, objeta Kripke, si tuviera una constitución molecular diferente, no sería justamente agua. Y entonces, es

${ }^{29}$ LU III, $\int$ 7; Hua, Bd. XIX/2, pp. 242-243; trad. citada, II, 2, p. 22. 
absolutamente necesario, necesario en el sentido más fuerte del término, que el agua sea $\mathrm{H} 2 \mathrm{O}$. Esto vale para muchas verdades empíricas (el calor es la energía cinética media de las moléculas, la luz es un flujo de fotones, etc.), pero también para las leyes de la naturaleza que de allí se derivan.

A primera vista, la afirmación de Kripke parece contradecir nuestras intuiciones más comunes, ya que confiere a una verdad empírica el mismo carácter de necesidad que a " $2+2=4$ " o a " $A \& B$ es verdadero si $\mathrm{A}$ es verdadero y B es verdadero". ¿Qué argumentos aporta Kripke en apoyo de una tesis tan paradójica?

Sin entrar en toda la sofisticación logico-semántica del ciclo de conferencias que hizo célebre a Kripke y que fue transcripto bajo el título Naming and Necessity, se puede decir que esta tesis deriva de dos grandes principios:

1) Una cierta concepción de la referencia de los nombres concebidos como "designadores rígidos".

2) El teorema lógico de la necesidad de la identidad. A partir de dos premisas, a) todo $x$ es necesariamente idéntico a él mismo y b) todo lo que es verdadero de algo es verdadero para cualquier cosa idéntica a esa cosa, se concluye que si $a$ es idéntico a $b$, entonces $a$ es necesariamente idéntico a $b^{30}$.

$\mathrm{Si}$ se considera, por un lado, que "agua" y " $\mathrm{H} 2 \mathrm{O}$ " son expresiones que funcionan como designadores rígidos, es decir, como términos que, si se refieren a algo, se refieren al mismo objeto en todos los mundos posibles ${ }^{31}$, y si se afirma, por otro lado, el juicio de identidad "agua $=\mathrm{H} 2 \mathrm{O}$ ", resulta que esta identidad, en virtud de la demostración de la necesidad de la identidad, vale en todos los mundos posibles y por lo tanto es metafísicamente necesaria.

A los ojos de Kripke, no serviría de nada objetar que esta necesidad es descubierta empíricamente. Porque Kripke rechazaría, como se ha visto, la transición de modalidades epistémicas a modalidades "metafísicas": de que haya descubierto una cosa empíricamente, a posteriori, es decir, de que la

30 La logique des noms propres, p. 98.

31 Ibid., p. 36: 'Llamaremos a algo 'designador rígido' si en todos los mundos posibles designa el mismo objeto". 
hubiera podido descubrir diferente (sentido epistémico de “poder"), no se deriva en absoluto que lo que he descubierto no sea necesario en el sentido fuerte del término, es decir, verdadero en todos los mundos posibles. No sirve de nada entonces objetar que, puesto que mi descubrimiento es empírico, yo podría concebir un mundo donde el agua no tuviera como constitución molecular dos átomos de hidrógeno y un átomo de oxígeno. Porque hay que ponerse de acuerdo sobre qué significa aquí "yo podría concebir". No hay ninguna duda de que, puesto que la verdad en cuestión es a posteriori, es epistémicamente contingente: otro descubrimiento hubiera sido posible. Pero, dado que el agua posee esta constitución, posee necesariamente esta constitución, porque todo lo que no posee esta constitución molecular en otros mundos posibles, cualquiera sea su semejanza con el agua, simplemente no es agua. Por supuesto, la física habría podido equivocarse hasta el presente sobre la composición química del agua e incluso sobre todas las constantes físicas fundamentales; hasta podría suceder que descubra un día que lo que refiere el nombre "agua" posee en realidad una composición atómica radicalmente diferente, llamémosla $x y z$, sin embargo, una vez que sabemos que la composición atómica del agua es $x y z$, si Kripke tiene razón, ya no podemos concebir un mundo donde esta constitución no sea $x y z$, porque toda sustancia que pudiéramos concebir y que tuviese una diferente composición atómica sería diferente al agua.

Uno se puede preguntar si esta conclusión no es trivial. En efecto, si se parte de la idea de que un designador rígido es una expresión que, si designa un objeto, designa el mismo objeto en todos los mundos posibles, se vuelve trivial concluir que, si $a$ y $b$ son idénticos, entonces son necesariamente idénticos, puesto que ya se postuló al principio que " $a$ " y " $b$ " se referían a los mismos objetos en todos los mundos posibles, y, por lo tanto, si eran idénticos, eran necesariamente idénticos. Todo el problema reside en realidad aquí, en la cláusula adicional: "una vez que sabemos que el agua es $\mathrm{H}_{2} \mathrm{O}$ ". Es esta cláusula la que introduce un elemento nuevo, volviendo así no trivial la demostración que precede. En efecto, a través de este inciso, Kripke parece considerar adquirida la idea de que la única manera que tenemos de identificar algo en todos los mundos posibles, es decir, la única manera que tenemos de conocer su naturaleza es lo que nos enseña la ciencia ( $y$ en este caso, lo que descubre una ciencia empírica particular, la física). La ciencia es la que descubre la esencia, y solamente ella. Si no se le concede este punto, si se afirma que hay otras maneras de saber 10 
que es el agua además de los descubrimientos empíricos de la ciencia, ya no es posible concluir tan fácilmente que lo que no es $\mathrm{H} 2 \mathrm{O}$ en otro mundo posible "parece" agua, pero "no es" agua.

Habría pues varias maneras de rechazar las conclusiones de Kripke: sea rechazando su teoría de la referencia; sea negando el teorema lógico de la necesidad de la identidad; sea negando simplemente que la ciencia y sólo ella tenga derecho de enseñarnos la naturaleza de algo. Quizás sencillamente no hay algo como la naturaleza de algo, una vez hecha la abstracción de todo interés teórico y de todo presupuesto.

En efecto, si sólo la ciencia pudiera enseñarnos lo que es el agua, habría que inferir de eso que los hombres no supieron jamás lo que era el agua antes del descubrimiento de su constitución molecular. Pero si tal fuera el caso, es muy difícil ver lo que la ciencia contemporánea habría podido descubrir, porque ya hay que saber lo que es el agua para poder descubrir algo al respecto. Esa sería seguramente una parte de la respuesta de Husserl: si yo no supiera ya lo que es el agua de manera precientífica (un líquido transparente, incoloro e inodoro, desprovisto de gusto, que puede existir a veces bajo forma sólida de hielo, que se evapora cuando se lo calienta, etc.) jamás podría descubrir empíricamente nada a propósito de ella, porque no podría saber siquiera a propósito de qué descubro lo que descubro. La ciencia (empírica) no puede poseer el monopolio de la esencia. En otros términos, tiene que haber esencias materiales, incluso inexactas, incluso reducidas a simples "tipos" como es el caso del agua -esencias que no requieran, para ser captadas, ninguna teoría física particular-, para que haya también “esencias" en el sentido de Kripke, es decir, los constituyentes últimos de las cosas descubiertas empíricamente. Pero todas las esencias precientíficas que estructuran nuestra experiencia ordinaria del mundo no son sin embargo vagas e inexactas. Porque la esencia "agua" pertenece al género "cosa material" o "cosa física" y se subordina así a los axiomas ontológicos regionales. Para saber lo que es el agua de manera precientífica hay que saber a priori otras cosas, por ejemplo, lo que es un cuerpo material, que todo cuerpo material es extenso espacialmente, etc.

En suma, para responder a Kripke, es posible seguir dos estrategias. La primera consiste en entrar en toda la sofisticación de su construcción lógico-semántica y en criticar tal o cual aspecto. Por ejemplo, se puede negar que los juicios de identidad que toma por ejemplos («El agua es $\mathrm{H} 2 \mathrm{O}$ », «El 
número atómico del oro es 79 », «La luz es un flujo de protones») contengan dos designadores rígidos. Se puede objetarle que contienen en realidad al menos una descripción: "El agua es $\mathrm{H}_{2} \mathrm{O}$ " no es más que una manera elíptica de decir "el agua es la sustancia física compuesta de moléculas de H2O"; en tal caso, la prueba de la necesidad de la identidad no puede aplicarse ya, dado que se aplica sólo a identidades entre dos designadores rígidos. Uno se puede preguntar entonces si todo en esta proposición ("El agua es la sustancia física compuesta de moléculas de $\mathrm{H} 2 \mathrm{O}$ ”) es conocido de una manera empírica. Desde luego descubrimos empíricamente que el agua es una molécula compuesta de dos átomos de hidrógeno y de un átomo de oxígeno. Pero sin duda no es empíricamente que descubrimos que el agua es una sustancia física o que es una cosa material de un cierto tipo; en efecto, si descubriéramos esto también empíricamente, nos sería imposible decir a qué se refiere tal descubrimiento. $Y$ si uno admite que al menos ciertas esencias no son descubiertas empíricamente sino que delimitan lo que es una cosa antes de todo descubrimiento empírico respecto de ellas, ya no es posible afirmar que una vez planteado que el agua es $\mathrm{H} 2 \mathrm{O}$ lo que posiblemente no es $\mathrm{H} 2 \mathrm{O}$ no es tampoco agua, dado que ya no hay una sola y una única manera de aprehender lo que es el agua, independientemente de todo interés teórico particular (no siendo el de la física más que un interés entre otros).

Sin embargo, esta estrategia compleja tal vez no es necesaria. Una segunda vía, más directa, consiste en hacer valer que, incluso concediendo a Kripke su aparato lógico-semántico sofisticado, la conclusión no se deduce, a menos que uno se adhiera a la idea de inspiración positivista según la cual sólo la ciencia puede descubrir lo que es el agua. Con el fin de precisar esta respuesta es útil, sin duda, intentar dilucidar antes los puntos de desacuerdo entre Kripke y Husserl. Son por lo menos cuatro: 1) la diferencia a priori/a posteriori, 2) la diferencia necesario/contingente; 3) la caracterización de la esencia; 4) el problema de saber si hay que diferenciar o no conceptos fenomenales y conceptos científicos.

1) Para Husserl, las verdades de esencia son anteriores a las verdades de experiencia, las posibilidades de esencia preceden a las realidades; lo que no quiere decir que el a priori no pueda ser descubierto (en el sentido de un descubrimiento no empirico: es en este sentido que el teorema de Pitágoras fue "descubierto"), porque hay que recordar una vez más que es a priori para Husserl no lo que de becho no es conocido por experiencia, sino lo que no 
tiene necesidad de investigaciones empíricas (ni de hipótesis empíricas) para ser conocido. Por tanto, es a priori lo que puede ser conocido sin recurrir a investigaciones o a hipótesis empíricas. Ahora bien, Kripke rechaza expresamente este empleo del a priori-que era ya el de Kant- según el cual son a priori las verdades "que uno puede conocer independientemente de toda experiencia"32, y, para definir la expresión "a priori", se apoya en "la cuestión de saber si una persona o un sujeto de conocimiento particular conoce algo a priori, o cree, sobre una base a priori, que algo es verdadero" 33 , es decir, en la manera en la que conoce efectivamente esta verdad. ¿Por qué Kripke desecha ese sentido tradicional de "a prior"? Este rechazo es evidentemente esencial para toda su empresa: si se elige, en efecto, la interpretación tradicional, lo que puede ser conocido sin recurrir a la experiencia es también lo que no puede ser contradicho por ninguna experiencia, por tanto lo que es verdadero en todos los mundos posibles; " $a$ prior" se vuelve así sinónimo ${ }^{34}$ de "necesario". Ahora bien, Kripke quiere mostrar que todo lo que es a priori no es necesario y que todo lo que es necesario no es a priori.

2) Para Husserl la distinción necesario/contingente epistémica es íntimamente solidaria con la distinción necesario/contingente ontológica, dado que el a priori es de alguna manera "analíticamente" necesario y lo necesario es de alguna manera "analíticamente" a priori. Ocurre de otro modo con Kripke, justamente porque rechaza la "sinonimia" en cuestión.

3) Kripke define la esencia en términos modales. Es esencial una propiedad verdadera en todos los mundos lógicamente posibles. "Algunas propiedades de un objeto pueden serle esenciales, en la medida en que no haya podido no tenerlas" 35 . "Esencial" es entonces para él sinónimo de "necesario". Así, por un lado, Kripke quiebra la equivalencia entre a priori y necesario, a posteriori y contingente, y, por el otro, instaura una nueva equivalencia, esta vez entre "necesario" y "esencial". Si la ciencia consigue actualizar propiedades necesarias, entonces consigue también actualizar propiedades esenciales, y recíprocamente.

32 La logique de noms propres, p. 23 (señalamos "puede").

33 Ibid.

34 Ibid., p. 26.

35 Ibid., p. 41. 
Para Husserl, esta consecuencia no es buena, como se ha visto, dado que rechaza justamente toda caracterización modal de la esencia. "Propiedad necesaria" y "propiedad esencial" sencillamente no son sinónimas. En consecuencia, aunque "el agua es $\mathrm{H} 2 \mathrm{O}$ " exprese una propiedad necesaria del agua (Husserl no concedería que la verdad de esta proposición es necesaria en el mismo sentido que las verdades materiales a prior $)$, esto no entraña sin embargo para Husserl que se trate allí de una propiedad de esencia. Se trata, más bien, de una propiedad que se funda en la esencia -por tanto presupone esta esencia para poder ser empíricamente descubierta.

Pero las concepciones de la esencia de los dos autores discrepan todavía en otro punto. Si uno examina los ejemplos con los cuales Kripke ilustra su propósito (el número atómico del oro, la luz como flujo de protones, el tigre como mamífero, el calor como energía cinética media de las moléculas), se percibe que todos esos ejemplos se relacionan con una concepción bien determinada de esencia, la que nace en la tradición lockeana, donde la "esencia" significa en realidad la "constitución real de las cosas"36. La esencia de Kripke es sólo una variante de la de Locke: las esencias son las propiedades profundas que una cosa debe tener necesariamente y que explican sus propiedades de superficie. Como lo escribe Locke, "en las sustancias en general, la constitución real, interior y desconocida de las cosas de la que dependen las cualidades que se pueden descubrir allí, puede ser llamada su esencia. Es el propio y originario significado de esta palabra" 37 - una significación distinta de la de la Escuela. Así, implícitamente, el esencialismo kripkeano se vincula con la tradición lockeana y no con la tradición platonico-aristotélica a la cual pertenece Husserl. Este último admitiría, por supuesto, que la ciencia nos permite descubrir empíricamente la constitución real de las cosas, pero se negaría a llamar a eso, sin más precauciones, su esencia. Diría, una vez más: para poder descubrir empíricamente que el agua es $\mathrm{H}_{2} \mathrm{O}$ ya hay que poseer una comprensión de su esencia, por ejemplo saber a priori que el agua es una sustancia física, y una sustancia física que posee tal o cual determinación fenomenal, porque de otro modo, sería precisamente imposible descubrir por la experiencia lo que es $\mathrm{H} 2 \mathrm{O}$, es decir, identificar el líquido en cuestión.

${ }^{36}$ Locke, Essai philosophique concernant l'entendement bumain, trad. Pierre Coste, París, Vrin, 1994, libro III, ch. III, \$15, p. 335.

${ }^{37}$ Ibid., libro III, ch. III, $₫ 15$, p. 334. 
4) Finalmente, Kripke rechaza un punto que constituye verdaderamente el corazón de la concepción de Husserl, la idea de que tendría sentido distinguir los conceptos fenomenológicos y los conceptos científicos. Escribe, por ejemplo: ciertos filósofos anticipan "la idea de que hay en realidad dos conceptos de metal, un concepto fenomenológico y un concepto científico que lo sustituye. Ahora bien, es una idea que rechazo" 38 . $\mathrm{Si}$, en efecto, las esencias son los constituyentes escondidos de las cosas, ellas no son accesibles más que a la ciencia, y todo lo que nos permite decir lo que es algo desde el punto de vista de nuestra experiencia primordial y ordinaria del mundo, no merece justamente ser llamado "esencia". Es el elemento que hemos llamado "positivista" de su concepción.

No tenemos la ambición de discutir cada uno de estos puntos. Algunos aspectos de la concepción de Kripke descansan en cuestiones extremadamente pertinentes que formula en contra de la tradición filosófica, tal como la posibilidad de una distinción entre necesario y a priori. Otros, en cambio, se parecen más bien a presupuestos no examinados de su propia doctrina. Por ejemplo, su definición lockeana de esencia o la idea según la cual es la ciencia y sólo ella la que nos enseña la verdadera naturaleza de las cosas. Esta idea no se deriva ni del análisis de los designadores rígidos ni del teorema de la necesidad de la identidad puesta al descubierto por Ruth Barcan Marcus. Ahora bien, es porque afirma que la ciencia nos permite conocer la naturaleza de las cosas (en singular y sin más especificaciones), que Kripke puede inferir ciertamente de eso que, si tal es la esencia del agua, el calor, etc. en este mundo, es también su esencia en todos los mundos posibles.

Porque finalmente, ¿hay verdaderamente algo como la naturaleza del agua? ¿No es preciso distinguir entre la naturaleza de este elemento tal como se nos presenta cada día en nuestra experiencia de las cosas y la naturaleza del agua tal como la analizan el físico o el químico? ¿No deben haber primero esencias precientíficas (y entre ellas, esencias puras a priori) para que haya, solamente entonces, esencias en el sentido empírico -esencias en el sentido de Locke? Para tomar otro ejemplo que Kripke comenta detenidamente, ¿la verdad de la proposición de identidad 
"Hesperus=Phosphorus" (en el cual "Hesperus" y "Phosphorus" son los nombres griegos de la estrella de la mañana y de la estrella de la tarde, es decir dos nombres de Venus), es conocida -o cognoscible- totalmente $a$ posteriori? Como lo observa Jonathan Lowe, esta

identidad ha sido establecida porque los astrónomos descubrieron que las órbitas de Hesperus y de Phosphorus coinciden: allí donde se encuentra Hesperus, en cualquier momento, Phosphorus se encuentra también. Sin embargo, la coincidencia espacio-temporal sólo implica identidad para cosas de especies apropiadas. Es solamente porque Hesperus y Phosphorus son considerados planetas, y por tanto objetos materiales de la misma especie, que su coincidencia espacio-temporal implica su identidad. Pero el principio de que objetos materiales distintos de la misma especie no pueden coincidir espacio-temporalmente no es empírico: es un principio a priori que se sigue de lo que es ser un objeto material de una cierta clase -en otros términos, es una verdad fundada en la esencia ${ }^{39}$.

Encontramos aquí muy exactamente los axiomas materiales de Husserl que preceden todas las hipótesis de la ciencia, rigiendo nuestra experiencia precientífica de las cosas y haciendo posibles, solamente en un segundo tiempo, todos los descubrimientos empíricos que podemos hacer al respecto.

Por supuesto, se podría objetar que la distinción científica/precientífica es una distinción vaga: ¿no comienza la ciencia con la percepción? Pero lo importante es observar que nada, en lo que adelanta Kripke, proporcionó el menor argumento para desechar la idea de esencias a priori. Tal vez no todas las esencias tienen ese estatus. Tal vez hay esencias descubiertas empíricamente (vamos a volver sobre ello en un instante), pero, en todo caso, no parece que la inexistencia de esencias a priori, especialmente de esencias a priori materiales, se derive de los argumentos que adelanta. Kripke, a decir verdad, no considera esa posibilidad en ningún momento.

${ }^{39}$ Jonathan Lowe, "La métaphysique comme science de l'essence", trad. francesa Roger Pouvet, en Métaphysique contemporaine. Propriétés, mondes possibles et personnes, textes réunis par Emmanuelle Garcia et Frédéric Nef, Paris, Vrin, p. 101. 
De hecho, en escasos textos Husserl parece reconocer que ciertas esencias pueden ser descubiertas empíricamente, pero no son las que interesan en más alto grado al fenomenólogo. En Experiencia y Juicio se lee, por ejemplo: 'La pertenencia del animal llamado 'ballena' a la clase de mamíferos es enmascarada por una analogía exterior que presenta con los peces en cuanto a su modo de vida, lo que ya se señala en la designación verbal [Walfisch en alemán]. En casos semejantes, hablamos de tipos no esenciales (...) Hay necesariamente en su fundamento [i.e. de la ciencia] la tipología no esencial de numerosos aspectos de la percepción inberente a la experiencia natural'40. Aquí, la tipología ingenua que asigna a la ballena el estatus de pez no es más que una tipología no esencial: no señala ni esencias propiamente hablando (ya que es empíricamente falsa), ni a fortiori esencias puras. Cuando el biólogo marino descubre que la ballena es un mamífero, sustituye esa tipología ingenua por un concepto científico, descubre empíricamente un rasgo esencial de la especie "ballena". Este descubrimiento empírico es entonces un descubrimiento de esencia: todas las esencias no son pues a priori. Estas esencias que no son a priori son designadas en el léxico de Husserl con el nombre de "generalidades empíricas"41.

Por consiguiente, sólo las esencias puras son para Husserl auténticamente a priori. Y si hay "esencias empíricas", o por lo menos esencias actualizadas por las ciencias empíricas, ellas presuponen las primeras y no tienen el mismo género de necesidad que éstas. ¿Cuál es exactamente el estatus de necesidad de las verdades actualizadas de manera empírica, o al menos de algunas de ellas? ¿Hay verdades físicas, por ejemplo, que sean incondicionalmente necesarias? Sobre este punto, el debate permanece abierto, y mi ambición no era resolverlo.

Es ciertamente un gran mérito de Kripke haber hecho temblar la evidencia supuesta de la equivalencia a priori-necesario, a posteriori-contingente, y a ese respecto, su contribución filosófica mayor consiste en principio en forzarnos a precisar estos conceptos en vez de pretender volver a un estado "adámico", anterior a Kripke, donde incluso no habría sitio para tales

40 E. Husserl, Erfabrung und Urteil, Hambourg, Glaassen \& Goverts, 1954, p. 402; trad. francesa Denise Souche, Expérience et Jugement, Paris, PUF, 1970, p. 405.

${ }^{41}$ Sobre las generalidades empíricas, cf. infra, capítulo II, nota 41. 
cuestiones (lo que traté de hacer especificando los lazos esencia/modalidad en Husserl).

Hay otro punto de gran importancia que se desprende de cuestiones planteadas por Naming and Necessity. Se adhiera o no a su concepción de conjunto, Kripke mostró, para mí de manera convincente, que el hecho de que algo sea concebible no entraña necesariamente que sea posible; o, para decirlo en sus términos: el hecho de que algo sea epistémicamente concebible no entraña necesariamente que sea metafísicamente posible. Restituyó así toda su complejidad a los lazos entre concebibilidad y posibilidad $^{42}$.

Es seguramente un límite de la concepción husserliana de la esencia que ella identifique pura y simplemente concebibilidad $-\mathrm{y}$ de hecho imaginabilidad - y posibilidad: todo lo que es concebible sería posible, todo lo que es posible sería concebible. Todo el procedimiento de la variación eidética descansa en esta equivalencia. Ahora bien, habría que objetar a Husserl dos cosas. Primero, todo lo que es imaginable prima facie no es sin embargo posible, ni todo lo que es inimaginable, imposible. ¿No es posible imaginar cosas imposibles? ¿La máquina para remontarse en el tiempo de H.G. Wells, por ejemplo? ¿No es imaginable que un personaje se remonte en el tiempo y que cambie el curso de la historia? ¿Que eso sea imaginable entraña que sea posible? Husserl respondería sin duda que un estado de cosas de este tipo es empíricamente imposible, pero no eidéticamente imposible. Pero esta respuesta no es defendible si el único criterio del que disponemos para actualizar lo eidéticamente posible es justamente lo que es posible e imposible imaginar (sin más especificaciones). En segundo lugar, parece muy difícil decir lo que es concebible e inconcebible, imaginable e inimaginable, sin hacer intervenir consideraciones suplementarias. Para el kripkeano, en virtud de sus presupuestos de partida, un agua que no fuese $\mathrm{H} 2 \mathrm{O}$ no es concebible en el sentido fuerte del término, es decir, metafísicamente posible. Para un husserliano, al contrario, en virtud de su caracterización de la esencia, lo es. ¿Cómo resolver esto?

42 Sobre esta complejidad, ver T. S. Gendler y J. Hawthorne (eds.), Conceivability and Possibility, Oxford, Clarendon Press, 2002 y especialmente la contribución de Kit Fine, "The Varieties of Necessity", que examina, para rechazarla, la tesis de Kripke sobre el estatus de las necesidades naturales. 
La única manera de resolverlo es poniendo en juego una argumentación filosófica. Pero si es imposible resolverlo sin una argumentación, la consecuencia es que la variación eidética no puede ser sencillamente $e l$ método, ni incluso un método, para actualizar las esencias y las necesidades de esencia. La variación eidética sólo sería un buen método en fenomenología si uno pudiera establecer por un argumento a priori que lo concebible (lo imaginable) y lo posible eidética o esencialmente son coextensivos. Pero esta demostración, aunque ella pudiera ser llevada a buen término, debería ya poner en juego una argumentación filosófica, por tanto premisas implícitas en parte no examinadas. En filosofía -tal es quizás el problema, pero es un problema que hace falta poder reconocer y afrontarno hay ni comienzo ni fin al logon didonai. Es por lo que todo método dogmático que pretendiera disponer de un procedimiento exento de toda presuposición y susceptible de proporcionarnos verdades sustraídas a toda duda posible no es más que una fantasía de filósofo y un método ficticio.

El descubrimiento de esencias supone necesariamente una dimensión argumentativa. No hay más que una manera en filosofía de actualizar verdades esenciales: por medio de argumentos más poderosos y más convincentes. Las propiedades de esencia no están inscriptas de una vez por todas en el espíritu eterno de alguna divinidad tutelar, ellas apelan al único método posible en filosofía, el de la discusión razonada, por lo tanto, a la crítica de las concepciones concurrentes.

Recibido: 10/2011 Aprobado: 4/2012 